\title{
Erratum to: Two cases of benign esophageal schwannoma with positive FDG-PET findings
}

\author{
Toshinobu Nakatsu - Satoru Motoyama - Kiyotomi Maruyama • \\ Yusuke Sato - Shuetsu Usami - Kei Yoshino • Hajime Saito • \\ Yoshihiro Minamiya $\cdot$ Hiroshi Nanjo $\cdot$ Jun-ichi Ogawa
}

Published online: 26 May 2012

(C) The Japan Esophageal Society and Springer 2012

Erratum to: Esophagus (2011) 8:289-293

DOI 10.1007/s10388-011-0290-8

The editors of Esophagus regret that the quality of Figs. 3 and 6 in the published article was not adequate for reproduction in the print version. Higher-resolution figures with new layouts are shown on the following page. They will be reproduced in color in the print version. The figure legends have been revised appropriately for the re-submitted figures.

The online version of the original article can be found under doi:10.1007/s10388-011-0290-8.

T. Nakatsu $(\bowtie) \cdot$ S. Motoyama · K. Maruyama · Y. Sato ·

S. Usami · K. Yoshino · H. Saito · Y. Minamiya - J. Ogawa Department of Surgery,

Akita University Graduate School of Medicine,

1-1-1 Hondo, Akita 010-8543, Japan

e-mail: to4nob_nakatz@yahoo.co.jp

K. Yoshino $\cdot$ H. Nanjo

Department of Pathology,

Akita University Graduate School of Medicine,

Akita, Japan 
Fig. 3 a The resected tumor was $50 \times 30 \times 30 \mathrm{~mm}$ in size, and the cut surface was yellowish, homogeneous and elastic firm. b Histological examination revealed nuclear palisading and lymphoid cuffing. c Immunohistochemically, the tumor was positive for S-100 protein
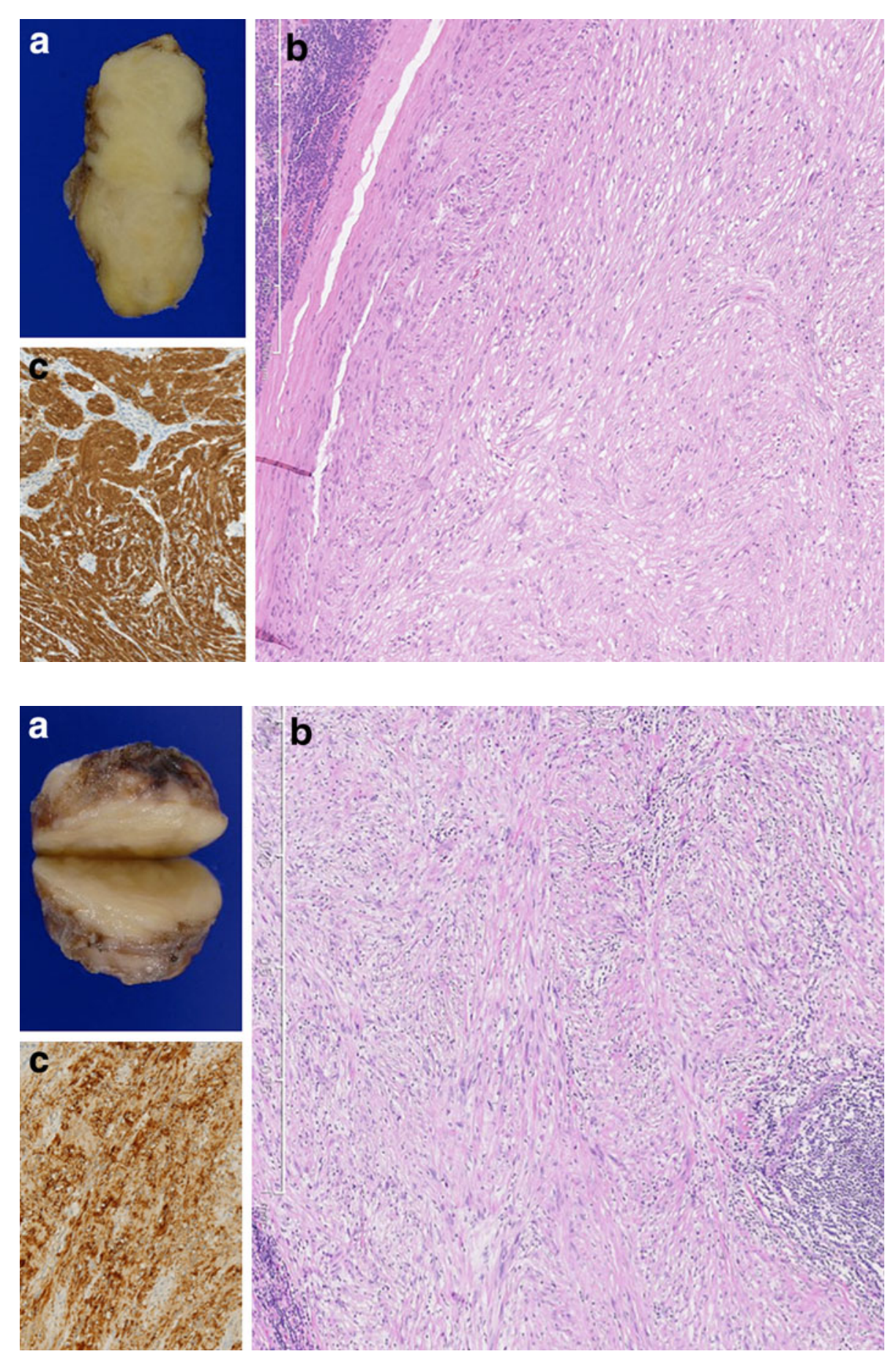

Fig. 6 a The resected tumor was $40 \times 35 \times 27 \mathrm{~mm}$ in size, and the cut surface was yellowish, homogeneous and elastic firm. b Histological examination revealed nuclear palisading and lymphoid cuffing. c Immunohistochemically, the tumor was positive for S-100 protein 